\title{
El clasismo a la defensiva: represión y resistencia (Córdoba, 1974-1976)
}

\section{Clasismo on the defensive: repression and resistance (Córdoba, 1974-1976)}

\author{
María Laura Ortiz \\ Consejo Nacional de investigaciones Científicas y Técnicas \\ Universidad Nacional de Córdoba \\ (Argentina) \\ malauraortiz@gmail.com
}

En este artículo se analizan las formas de organización de los nucleamientos sindicales clasistas a partir del cambio de coyuntura político de 1974 en Córdoba. A partir de ese momento, la represión política y económica comienza a golpear duro en las organizaciones sindicales clasistas y combativas. No obstante, se desplegaron diferentes formas de resistencia, aglutinadas sobre todo en la Mesa Coordinadora de Gremios en Lucha.

Palabras Clave: Clasismo - Violencia - Represión - Mesa de Gremios en Lucha - Córdoba

\begin{abstract}
This article describes the organization forms of the "clasistas" trade union associations since the transformation of the political situation in Córdoba in 1974. Since that moment, the political and economic repression started to hit hard on the combative unions "clasistas". However, different forms of resistance were deployed, specially from the Mesa Coordinadora de Gremios en Lucha.
\end{abstract}

Key Words: Clasismo - Violence - Repression - Mesa de Gremios en Lucha - Córdoba 


\section{Introducción}

En la mayoría de las investigaciones desarrolladas sobre la clase obrera argentina en la historia reciente se sostiene que, a partir de 1969, se produjo un proceso de radicalización en el que el "clasismo" fue su máximo exponente. ${ }^{1}$ No obstante, al momento de abordarlo, las pesquisas se han focalizado en estudios de caso en los que se describen algunos hechos y sus principales protagonistas. En lo referido a Córdoba, las indagaciones se circunscribieron al Sindicato de Trabajadores de FIAT Concord y Materfer (SiTraC y SiTraM) entre 1970 y 1971 y al del Sindicato de Mecánicos y Afines del Transporte Automotor (SMATA) entre 1972 y 1974. Estos fueron casos que repercutieron en diversos puntos del país y, evidentemente, su trascendencia fue posible gracias al éxito en la estrategia de los clasistas para alcanzar la dirección sindical. Sin embargo, este fue un fenómeno más amplio y se nutrió de distintas

1. BRENNAN, James, "El clasismo y los obreros. E1 contexto fabril del 'sindicalismo de liberación' en la industria automotriz cordobesa, 1970-75", en Desarrollo Económico, Buenos Aires, 1992, V.XXXII, No 125, pp. 3-22; LÖBBE, Héctor, La guerrilla fabril: clase obrera e izquierda en la Coordinadora de Zona Norte del Gran Buenos Aires: 1975-1976, Ediciones RyR, Buenos Aires, 2009; LORENZ, Federico, Algo parecido a la felicidad. Una historia de la lucha de la clase trabajadora durante la década del setenta (1973-1979), Edhasa, Buenos Aires, 2013; POZZI, Pablo y SCHNEIDER, Alejandro, Los "setentistas". Izquierda y clase obrera (1969-1976), EUDEBA, Buenos Aires, 2000; SANTELLA, Agustín y ANDÚJAR, Andrea, El Perón de la fábrica éramos nosotros. Las luchas metalúrgicas de Villa Constitución, 1970-1976, Desde el Subte, Buenos Aires, 2007; WERNER, Ruth y AGUIRRE, Facundo, Insurgencia obrera en la Argentina 1969-1976. Clasismo, coordinadoras interfabriles y estrategias de la izquierda, Ediciones IPS, Buenos Aires, 2009. experiencias que surgieron en otros sectores de la industria y los servicios. En estos otros casos, los clasistas no llegaron más allá de la conformación de una agrupación sindical, de integrar cuerpos de delegados, comisiones internas de reclamos, o de formar sindicatos paralelos. Allí, el acceso a la comisión directiva del sindicato fue un camino vedado por diferentes obstáculos, que dependieron de las prácticas y estatutos de cada sindicato, como también de las condiciones sociopolíticas.

El estudio del fenómeno clasista debe considerar que las experiencias se fueron modificando de acuerdo a las cambiantes coyunturas políticas. Desde esta perspectiva, nos proponemos analizar las transformaciones que produjo el "Navarrazo" en Córdoba, que obligó al activismo clasista a organizarse de manera defensiva. Este golpe policial, sucedido el 28 de febrero de 1974, implicó el derrocamiento del gobierno provincial liderado por Ricardo Obregón Cano y Atilio López. ${ }^{2}$ En el mundo sindical también se puso en evidencia un cambio importante, ya que el mismo día del "Navarrazo", se realizó un plenario normalizador de la Confederación General del Trabajo (CGT) regional Córdoba. A partir de allí, su secretariado quedaría conformado por peronistas "ortodoxos" que se alinearon con la política del gobierno nacional. Mientras tanto, los casi 40 sindicatos que formaban parte de la anterior CGT (integrada por los peronistas "legalistas", "independientes" y "no alineados") llamaron a desconocer a la CGT "normalizada” y decidieron formar el Movimiento Sindical Combativo (MSC). Allí

2. SERVETTO, Alicia, "Córdoba en los prolegómenos de la dictadura. La política del miedo en el gobierno de Lacabanne", en Estudios, Córdoba, 2004, No 15, pp.143156. Disponible en: $<$ https://revistas.unc.edu.ar/index. php/restudios/article/view/13542/13710> 
se aglutinó al activismo clasista y combativo a partir de un programa de 10 puntos que incluía el llamado a elecciones, enjuiciamiento y castigo a Navarro, libertad a los presos políticos y gremiales, formación de una CGT local elegida democráticamente, cuestionamiento del Pacto Social, entre otros. Sin embargo, la composición de este nucleamiento quedó reducido, a partir de la intervención, a dos de sus principales sindicatos: Luz y Fuerza y SMATA. ${ }^{3}$

3. La Voz del Interior (LVI), Córdoba, 01/03/1974, p. 11; Ídem, 02/03/1974, p. 9; Córdoba, Córdoba, 01/03/1974, pp. 5, 11; “Los diez puntos del MSC”, 28/05/1974, Archivo de audio de Agustín Tosco. En ese momento, el MSC agrupaba a 12 sindicatos y 30 agrupaciones, y contaba entre sus aliados al Movimiento Sindical de Bases (MSB), el Frente Antiimperialista y por el Socialismo (FAS), el Movimiento Obrero Radical, el Partido Revolucionario de los Trabajadores (PRT), el Partido Comunista Revolucionario (PCR), Vanguardia Comunista (VC), El Partido Socialista de los Trabajadores (PST), La Juventud Peronista, el Peronismo de Base, la Federación Universitaria de Córdoba y otras agrupaciones políticas y estudiantiles. $L V I$, Córdoba, 14/03/1974, p. 18; ídem, 16/03/1974, p. 9; ídem, 28/03/1974, p. 11; Córdoba, Córdoba, 30/05/1974, pp. 1, 4. A fines de los años '60, los "ortodoxos" se definieron así para remarcar su adhesión intransigente a los principios peronistas y distinguirse del sector "legalista", más dispuesto a la negociación con el Estado y a competir por el liderazgo de Perón. Defendían el verticalismo como única forma de dar fidelidad incondicional a Juan Domingo Perón. Los "legalistas" se identificaban con una postura más progresista y, aunque también defendían la lealtad a Perón, cuestionaban la verticalidad a ultranza. Para ejercer una mayor representatividad sindical, los "legalistas" habían radicalizado su discurso a tono con las posturas de los "independientes" y "no alineados". Estos últimos aglutinaban a gremios no peronistas y reivindicaban un sindicalismo
Por ello, el objetivo de este trabajo es analizar las formas de organización de los nucleamientos sindicales clasistas a partir del cambio de coyuntura política de 1974 en Córdoba. Desde ese momento la represión política y económica golpeó duramente a los activistas clasistas y combativos, que en su mayoría perdieron los espacios institucionales de organización. No obstante, desplegaron diferentes formas de resistencia de manera autónoma respecto de las estructuras sindicales.

Las fuentes utilizadas para este artículo son de distintos tipos. Primero, se consultaron diarios y revistas de distribución masiva y publicaciones sindicales y políticas. De los periódicos $L a \mathrm{Voz}$ del Interior y Córdoba se registraron noticias sobre conflictos laborales, distintas medidas de fuerza, alineamientos políticos y conflictos internos en los sindicatos y hechos de represión a los trabajadores. Además, se ficharon datos publicados en revistas vinculadas a estas problemáticas: una de ellas es la revista Aqui y Ahora, representante de la visión de la ortodoxia peronista, que es útil para contraponer visiones de la realidad política y sindical del momento. También la revista Hechos y Protagonistas de las Luchas Obreras Argentinas dedicó un número al desaparecido Renée Salamanca, dirigente del SMATA Córdoba, presentando una importante cantidad de información sobre el sindicato y sus cuerpos orgánicos. Eso fue complementado con alguna prensa sindical y partidaria, útiles para reconocer posicionamientos y evaluaciones políticas. Para ello también fue pertinente recurrir a

democrático, antiburocrático y con amplia participación de las bases. BRENNAN, James y GORDILLO, Mónica, Córdoba rebelde. El Cordobazo, el clasismo y la movilización social, De la Campana, Buenos Aires, 2008, pp. 34-47. 
discursos grabados en audio de dirigentes como Agustín Tosco, resguardados en el Archivo del Sindicato de Luz y Fuerza de Córdoba. Además, se revisaron expedientes judiciales conservados en el Archivo Histórico del Poder Judicial de Córdoba (CDHPJ). De todo el corpus documental, este trabajo refiere a un expediente iniciado con motivo de la desaparición de un delegado del Sindicato de Empleados Públicos, sucedido en 1975. Los testimonios allí recogidos ponen en evidencia la coordinación institucional y extrainstitucional para la represión de los trabajadores clasistas y combativos. Para ello también se consultaron los informes de la Comisión Nacional sobre la Desaparición de Personas (CONADEP), tanto a nivel nacional, como provincial.

Para analizar la realidad por fuera de las estructuras sindicales, las entrevistas nos abren una ventana a la vida cotidiana de los obreros $\mathrm{y}$ sus percepciones sobre su propia realidad. En palabras de Ronald Fraser, se trata de recuperar lo que la gente sentía y pensaba -o pensaba que pensaba-; que constituyen la base de sus actos. ${ }^{4}$ Se han realizado entrevistas a dirigentes y activistas de distintos sindicatos cordobeses referenciados con el clasismo. En esta labor, hemos tomado todas las precauciones metodológicas de la historia oral para trabajar con testimonios orales, considerando al lenguaje en su expresión oral como representante de un conjunto de sistemas de significación que no solo refieren a la individualidad del que está hablando si no que, sobre todo, representa las redes sociales en las que ese individuo participa. ${ }^{5}$

4. FRASER, Ronald, Recuérdalo tú y recuérdalo a otros. Historia oral de la guerra civil española, Crítica, Barcelona, V. I, 1979, pp. 26, 29.

\section{LARA MEZA, Ada Marina, MACÍAS GLORIA,} 64

\section{La intervención del SMATA Córdoba y la autonomización de los cuerpos orgánicos}

En el clima del post "Navarrazo"se realizaron las elecciones sindicales del SMATA Córdoba ${ }^{6}$ y volvió a ganar el Movimiento de Recuperación Sindical (MRS) - Lista Marrón. Este núcleo clasista, que había resultado triunfador en las elecciones sindicales por primera vez en 1972, se hallaba en un contexto diferente no solo por el cambio político de la provincia sino también por la situación sindical y específicamente, del gremio mecánico. Por un lado, la "ortodoxia" peronista se hallaba con un nuevo poder luego del plenario de la CGT y había aglutinado a gran parte del peronismo en la Lista Gris. Su programa se paraba en la vereda contraria al MRS y acusaban de "ideólogo vendepatria"

Felipe y CAMARENA OCAMPO, Mario (coordinadores) Los oficios del historiador: taller y prácticas de la historia oral, Universidad de Guanajuato, México, 2010; LAVERDI, Robson, "Raymond Williams y la historia oral: relaciones sociales constitutivas", en Palabras y silencios, México, 2010, V. V, N² 2, pp. 21-32; SCHWARZSTEIN, Dora (organizadora) La bistoria oral, CEAL, Buenos Aires, 1991.

6. En SMATA estaban encuadrados los trabajadores de una variada cantidad de fábricas dedicadas a la producción de automóviles, repuestos y accesorios; como también de trabajadores de concesionarias encargadas de la venta de los mismos. Entre ellas, la más importante era la planta de Renault instalada en barrio Santa Isabel, en el sur de la ciudad, donde trabajaban más de 10.000 obreros. Otras fábricas eran Transax, donde trabajaban casi 200 personas, Thompson Ramco con poco menos de 300, Grandes Motores Diesel con 540 obreros, ILASA y División Plantas Matrices-Perdriel con alrededor de 400 trabajadores cada una, e ILASA PBC con 150 trabajadores. Entre las concesionarias estaban: Agro Automotores, Piattini, Vicente Manzi y Tagle, Pablo García, Organización Automotor, Elías Sabagh y Cía. S.A., Calviño S.A., y otras. 
a su principal dirigente, Renée Salamanca, por haber propuesto el voto en blanco en las elecciones presidenciales del año anterior. ${ }^{7}$

A su vez, la Lista Marrón de 1974 no era la misma de 1972. Varios sectores que habían conformado el MRS se habían alejado, en medio de disputas por modelos de organización y por cuestiones político-partidarias. El Peronismo Descamisado y el Movimiento Obrero Radical, con apoyo del Partido Comunista (PC) y "las 62 legalistas", habían formado una lista propia, la Naranja. Unos meses antes de las elecciones, la Lista Marrón y la Naranja habían iniciado conversaciones para fusionarse, pero no lo lograron. No obstante, el Peronismo de Base (PB) apoyaba públicamente a la Lista Marrón ya que consideraba que la Naranja "dividía a la masa mecánica". ${ }^{8}$

Aunque los guarismos dieron un triunfo holgado a la Lista Marrón, no significaron estabilidad ya que las directivas de la central del SMATA venían dificultando la gestión de la seccional Córdoba. ${ }^{9}$ En primer lugar, demoraron en reconocer los resultados, lo que fue reclamado en varias asambleas y manifestaciones céntricas. En ellas también se pedían aumentos del salario por un $60 \%$ y un $3 \%$ en el escalafón por antigüedad, por lo que además se inició trabajo a convenio y quite de colaboración. El ministerio de Trabajo intimó al SMATA seccional Córdoba a levantar esas medidas de fuerza, ya que los pedidos de aumentos violaban el tope establecido por el

7. Córdoba, Córdoba, 07/04/1974, p. 5; Ídem, 06/05/1974, p. 3; Aqui y ahora, Buenos Aires, N 62, 1974, p. 35; Ídem, $\mathrm{N}^{\circ} 74 / 75,1975$, p. 22.

8. Córdoba, Córdoba, 07/05/1974, p. 5.

9. Ídem, 12/05/1974, p. 5; Hechos y Protagonistas de las luchas obreras argentinas, Buenos Aires, N 1, 1984, p. 16.
Pacto Social. ${ }^{10}$ La presión de estos funcionarios fue acompañada por acciones de represión empresarial: la firma suspendió a 902 operarios con el argumento de que las medidas de fuerza habían provocado la falta de materiales para el armado final de los vehículos. A los pocos días, aumentó el número de suspendidos a 1.194 y luego a 2.800 , entre los obreros de Renault e ILASA PBC. El sindicato argumentó que no eran medidas de fuerza sino "el cumplimiento riguroso -y exclusivode las obligaciones legales y convencionales vigentes para el gremio", esto es, el trabajo a reglamento. El MSC apoyó al SMATA y juntos realizaron un acto público en el centro para reclamar por un aumento salarial y para oponerse a "la dependencia, los monopolios y el imperialismo". ${ }^{11} \mathrm{El}$ conflicto entre la dirigencia clasista y las cúpulas sindicales nacionales, el Estado y la patronal duró más de cuatro meses y terminó con la expulsión de la Comisión Directiva cordobesa en un congreso del SMATA. La medida punitiva dejó acéfala la seccional y con sus fondos bloqueados, hasta que finalmente fue intervenida. ${ }^{12}$

10. E1 "Pacto Social" fue la cláusula fundamental de la política económica antiinflacionaria que instauró Juan D. Perón en su tercera presidencia. Por este acuerdo se congelaron las actualizaciones salariales para armonizar la configuración de precios, otorgando un aumento uniforme del 20\% y suspendiendo las convenciones colectivas por dos años. A su vez las empresas se comprometían a no aumentar los precios, aunque en muchos casos éstos se habían inflado preventivamente. BRENNAN, James y GORDILLO, Mónica, Córdoba rebelde..., Op. Cit., p. 186.

11. Córdoba, Córdoba, 12/07/1974, p. 5; ídem, 22/07/1974, pp. 3-4.

12. Ídem, 09/08/1974, pp. 1, 3; ídem, 15/08/1974, p. 4; ídem, 30/08/1974, p. 7. 
En este conflicto se evidenció el quiebre político que atravesaba el contexto histórico y que estaba determinado por la oposición ideológica entre izquierda y derecha. Luego de la destitución del gobierno provincial, identificado con el peronismo más progresista, los sectores vinculados a la derecha hegemonizaron las instituciones estatales $y$ sindicales, en alianza con el empresariado multinacional. A su vez, luego del "Navarrazo", las "fuerzas de seguridad" habían coordinado la represión y absorbido las modalidades de represión parainstitucional. En la vereda opuesta a este conglomerado de sectores dominantes, los clasistas resistieron, hasta donde les fue posible, apoyados por un cúmulo de fuerzas progresistas y de izquierda. ${ }^{13}$ Dentro del primer grupo, aquellos que se alinearon con la patronal mecánica, estaba incluida la CGT regional, como también la Lista Gris y la dirección del SMATA Córdoba "normalizado", controlados todos por los grupos peronistas "ortodoxos". A nivel nacional, estos discursos eran esgrimidos por las cúpulas sindicales, especialmente la CGT y "las 62 Organizaciones". Desde estos sectores, apoyados por el ministro de Trabajo Ricardo Otero, se comenzó a presionar a la seccional mecánica cordobesa para que depusiera

13. ORTIZ, María Laura, "Córdoba y sus vaivenes. Transformaciones coyunturales y continuidades estructurales en la relación entre Estado, empresarios y mundo obrero (1969-1976)", en Estudios, Córdoba, 2014, No 32, pp. 149-167. Disponible en: <https://revistas.unc. edu.ar/index.php/restudios/article/view/11588/12003> Para profundizar en cuestiones conceptuales sobre lo que aquí se refiere como "derecha" e "izquierda", cfr. ALTAMIRANO, Carlos, Peronismo y cultura de izquierda, Siglo XXI Editores, Buenos Aires, 2011; ARICÓ, José M., La cola del diablo. Itinerario de Gramsci en América Latina, Siglo XXI, Buenos Aires, 2014 [2005]; OLLIER, María Matilde, El fenómeno insurreccional y la cultura politica (1969-1973), CEAL, Buenos Aires, 1986. su actitud de lucha. ${ }^{14}$ En cambio, las bases mecánicas y gran parte de las organizaciones políticas de izquierda, apoyaban a los dirigentes mecánicos clasistas. Así lo hicieron en una asamblea multitudinaria donde se decidió continuar con trabajo a reglamento en reclamo por aumentos salariales y mejoras en las condiciones laborales. ${ }^{15}$

El trabajo a reglamento estaba, en efecto, entorpeciendo el normal funcionamiento de la producción, según las quejas de la patronal de Santa Isabel. Voceros vinculados a la empresa indicaron que en algunas secciones el ritmo del trabajo había disminuido en un 40 a $60 \%$. Unos días después, la empresa decidió aplicar suspensiones en ILASA Pajas Blancas y PBC y cerró más tarde la planta de Santa Isabel e ILASA por unos días. Cuando estas reabrieron, fue con presencia de Gendarmería dentro de los establecimientos, que fue resistida por las bases obreras con varios abandonos de tareas y manifestaciones. ${ }^{16}$

La posición del gobierno nacional y provincial estuvo en consonancia con el grupo empresarial. Por un lado, el ministerio de Trabajo reconoció la expulsión de los dirigentes cordobeses del SMATA Nacional y, además, dictó la conciliación obligatoria en el conflicto con la patronal. ${ }^{17}$ Por otra parte, la

14. Córdoba, Córdoba, 07/02/1974, p. 8; ídem, 20/07/1974, p. 2; Ídem, 25/07/1974, p. 3; Ídem, 07/08/1974, pp. 3, 5 .

15. Ídem, 23/07/1974, p. 5; ídem, 24/07/1974, pp. 1-2; ídem, 02/08/1974, p. 5.

16. Ídem, 23/07/1974, p. 5; ídem, 26/07/1974, p. 7; ídem, 03/08/1974, pp. 3-5, ídem, 04/08/1974, pp. 1-2; ídem, 06/08/1974, p. 3; ídem, 07/08/1974, p. 5.

17. Córdoba, Córdoba, 11/08/1974, p. 3; ídem, 12/08/1974, p. 5; ídem, 13/08/1974, p. 3; ídem, 14/08/1974, pp. 2-3; ídem, 16/08/1974, p. 5. 
política represiva se acentuó en contra de los sectores sindicales clasistas y combativos. En ese sentido, se profundizó el funcionamiento de los servicios de inteligencia y la policía local fue apoyada por la Guardia de Infantería y la División Antiguerrillera de la Policía Federal. ${ }^{18}$

A pesar de la represión y la expulsión, los trabajadores mecánicos y sus cuerpos orgánicos continuaron movilizados aunque, ante la imposibilidad de expresarse a través del Sindicato, el MSC hizo las veces de soporte institucional. Una asamblea de las bases acordó reconocer únicamente a la Comisión Ejecutiva que encabezaba Salamanca e intentaron resistir a la entrega del local sindical a los delegados normalizadores. ${ }^{19}$ No obstante, gracias a la intervención de la Justicia Provincial, de la Justicia Federal y, por cierto, del uso de la fuerza, los delegados normalizadores se apropiaron del local. Primero, el Juez Federal Zamboni Ledesma había dispuesto el allanamiento del local del SMATA seccional Córdoba ante una denuncia de los delegados normalizadores de que allí había "armas de guerra", lo cual no pudo ser comprobado luego del procedimiento policial. Antes de que se realizara el allanamiento, el SMATA Córdoba había presentado un recurso de amparo para evitar que la policía ocupase la sede sindical, pero el mismo Juez Zamboni Ledesma lo

18. Ídem, 23/07/1974, p. 5; ídem, 08/11/1974, p. 4; Juan Delgado, delegado de Renault, miembro de la Agrupación "26 de Julio”, entrevista realizada en Córdoba el 05/08/2010 por Laura Ortiz; Juan Villa, delegado y miembro de Comisión Directiva de Perkins, integrante de la Lista Marrón de Perkins, militante de Movimiento de Liberación Nacional, luego en El Obrero y más tarde en Poder Obrero, entrevista realizada en Córdoba el 29/08/2011 por Laura Ortiz.

19. Córdoba, Córdoba, 24/07/1974, pp. 1-2; ídem, 10/08/1974, p. 5; ídem, 18/08/1974, p. 4; ídem, 19/08/1974, p. 1; ídem, 20/08/1974, p. 7. había desestimado. Más tarde, el ministro de Gobierno José Mosquera emitió una orden para que los dirigentes expulsados abandonasen el recinto y se lo cedieran a los delegados normalizadores. Visto esto, los activistas y líderes desplazados ocuparon el local, mientras se declararon nuevos abandonos de tareas para movilizar las bases obreras que colaborarían en la custodia del sitio. Al mismo tiempo, enviaron a Buenos Aires una delegación que buscó contactarse con el Gobierno para destrabar el conflicto. Sin embargo, nada de eso fue efectivo, ya que finalmente, se firmaron dos órdenes de desalojo en simultáneo: una por la Justicia Provincial, firmada por el Juez de Instrucción Carlos Hairabedián y otra firmada por el ya citado juez Zamboni Ledesma. Cuando la policía quiso concretar las órdenes, tuvo que enfrentarse con grupos de afiliados del SMATA que quisieron resistir la medida judicial. Como consecuencia de los tiros que fueron disparados durante el procedimiento, resultaron heridas dos personas. Por otro lado, el local fue clausurado por unos días hasta que, finalmente, quedó en manos de los interventores. Su primera medida fue llamar a las bases a normalizar las tareas, prometiendo que si lo hacían la patronal dejaría sin efecto las suspensiones. En estas decisiones eran apoyados públicamente por la Juventud Sindical Peronista (JSP). ${ }^{20}$

Por su parte, el Cuerpo de Delegados mecánicos continuaba desconociendo la conciliación obligatoria, de manera que todas las plantas mecánicas trabajaban al 50\% y se organizaron abandonos, movilizaciones $\mathrm{y}$

20. Ídem, 21/08/1974, p. 5; ídem, 24/08/1974, p. 3; ídem, 26/08/1974, p. 1; ídem, 29/08/1974, p. 4; ídem, 31/08/1974, p. 3; ídem, 03/09/1974, p. 5; ídem, 04/09/1974, p. 4; ídem, 04/09/1974, p. 5; ídem, 11/09/1974, p. 4; ídem, 20/09/1974, p. 5. 
actos que continuaron con el reclamo salarial que había iniciado este conflicto. La patronal llegó a quejarse de que la disminución de la producción en Renault alcanzaba un 80\%. En la última semana de septiembre de 1974, la ex dirección del SMATA Córdoba convocó a una asamblea pero, ante la presencia policial, decidió anularla y realizar asambleas por fábrica. La división de las fuerzas debe haber sido un condimento sustancial para debilitar la movilización, amén del descontento obrero por los descuentos salariales y, finalmente, se decidió normalizar las tareas. Las plantas de GMD y Santa Isabel fueron los últimos bastiones de la resistencia, en donde se continuó con la "huelga de brazos caídos" por un tiempo más. ${ }^{21}$

La institucionalidad mecánica se alineó verticalmente a la nueva construcción hegemónica de la política. Así, hacia fines de 1974, los diarios informaban que dirigentes del SMATA nacional y algunos delegados de ILASA habían brindado un reconocimiento al interventor Brigadier Lacabanne. Un mes después, se descubría un busto de Perón y Evita en la misma planta, con la presencia de Lacabanne, el ministro de Trabajo Alejo Simó, otros funcionarios del gobierno, los sindicalistas Alfredo Martini y Mauricio Labat, etc.; todos ellos representantes del renovado predominio político y sindical del peronismo "ortodoxo". ${ }^{22}$

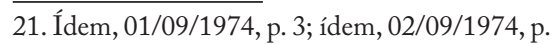
4; ídem, 03/09/1974, p. 5; ídem, 05/09/1974, p. 5; ídem, 11/09/1974, p. 4; ídem, 22/09/1974, p. 3; ídem, 23/09/1974, p. 5; ídem, 24/09/1974, p. 5; ídem, 25/09/1974, p. 7; ídem, 04/10/1974, p. 4.

22. Córdoba, Córdoba, 07/12/1974, p. 7; ídem, 11/01/1975, p. 4. Raúl Lacabanne fue el segundo interventor de la provincia en este período (07/09/1974 a 19/09/1975). Estaba identificado con el “clan” de López Rega por sus ideas "ultraverticalistas”. SERVETTO, Alicia, “Córdoba en los prolegómenos...”, Op. Cit., 68
Al mismo tiempo, se reforzó el discurso social legitimador de la represión en diarios, donde se presentaban noticias sobre "células extremistas" que actuaban en las fábricas mecánicas. La comisión normalizadora de SMATA sumaba renglones a los argumentos de ese discurso, cuando declaraba que el sindicato no lucharía por la libertad de los trabajadores que militasen en partidos de izquierda. Decía públicamente el delegado normalizador Orlando Armentano:

\section{El sindicato va a dar cobertura gremial durante las ocho horas de trabajo; aquellos compañeros que quieran practicar ideologías extranjeras, después de las 8 horas de trabajo, serán ellos responsables y la organización sindical no va a mover un dedo, porque aquellos que atentan contra el país están contra el SMATA. ${ }^{23}$}

Sin embargo, según la percepción de la policía infiltrada en el mundo obrero, la comisión normalizadora se hallaba "húerfana" de apoyos, mientras que la ex conducción era respaldada por "miles de trabajadores". ${ }^{24}$ Hasta mediados de 1975, la mayoría de las fábricas mecánicas continuaron movilizadas, aunque en todos los casos fue por reclamos defensivos: pedir la liberación de presos, exigir el levantamiento de las órdenes de captura contra dirigentes y activistas clasistas, organizar ayudas económicas para las familias de los trabajadores detenidos, denunciar desaparición de activistas y delegados, entre otras. En cada una de esas decisiones, los mecánicos fueron acompañados por los delegados combativos de Perkins, de FIAT Concord y Materfer, con quienes habían formado un único Cuerpo de Delegados.

pp.144-151.

23. Córdoba, Córdoba, 02/04/1975, p. 7.

24. Memorando Policía Federal, s/d [c. septiembre 1974]. 
En esa situación se produjeron las llamadas “jornadas de junio/julio de 1975". Aquellas grandes manifestaciones obreras desarrolladas especialmente en Buenos Aires, fueron mucho menos activas en Córdoba. En esta provincia, los sindicalistas nucleados en el peronismo "ortodoxo" -varios de ellos interventores en distintos gremios- convocaron a un paro total con movilización. Aunque de él participó la mayoría de las bases obreras de los núcleos fabriles, incluido el activismo que se aglutinaba en la Mesa Coordinadora de Gremios en Lucha, fue una marcha absolutamente controlada desde arriba. De esta manera, con las estructuras sindicales alineadas con el gobierno, la movilización de base fue sofocada eficazmente. Una nueva declaración de Estado de Sitio prohibió las concentraciones callejeras e ilegalizó los paros por cuestiones vinculadas a las paritarias. ${ }^{25}$

Esa violencia represiva era respondida con nuevos "atentados extremistas" contra integrantes del empresariado mecánico. Así, en septiembre de 1975, un comando disparó contra el auto del Jefe de Relaciones Laborales de Transax, Leonardo Alfredo Castelli, quien resultó herido. ${ }^{26}$ Pocos días después, un comando de los Decididos de Córdoba del ERP secuestró al Jefe de Personal de Transax, Julio César. Cuando lo liberaron, le dieron un plazo perentorio para que él y otros cuatro

25. Córdoba, Córdoba, 16/05/1975, p. 5; ídem, 10/06/1975, pp. 1, 5; ídem, 11/06/1975, p. 5; ídem, 12/06/1975, pp. 1, 5; ídem, 17/06/1975, p. 4; ídem, 19/06/1975, pp. 3-4; ídem, 25/06/1975, pp. 1, 4; ídem, 26/06/1975, pp. 1, 7; ídem, 28/06/1975, p. 5; ídem, 02/07/1975, p. 4; ídem, 13/08/1975, p. 7; "Bolita”, delegado de Tubos Transelectric, miembro de la Mesa de Gremios en Lucha, militante de Poder Obrero y FAS, entrevista realizada en Pilar, Córdoba el 26/10/2011 por Laura Ortiz y Ma. Paula Puttini.

26. Ídem, 04/09/1975, p. 1. funcionarios de Transax abandonasen el país, so pena de ejecución. ${ }^{27}$ Alrededor de un mes más tarde, un "grupo extremista" intentó secuestrar a Eduardo J. Jhones, gerente de relaciones laborales de Transax. Por la intervención de su custodia personal la acción fue frustrada y dos miembros del comando fueron detenidos. Por esos hechos, Transax contrató una empresa para que se ocupase de la seguridad en la planta y realizase custodias personales a sus directivos. $\mathrm{Al}$ parecer fueron más que eso, ya que algunas organizaciones políticas y sindicales acusaron a Transax de montar un aparato represivo interno que impedía la realización de asambleas, perseguía a sus trabajadores y amedrentaba a los activistas. ${ }^{28}$

Queda en evidencia entonces como los sectores patronales tuvieron un rol activo en la represión a los trabajadores. También que ello fue considerado un motivo para "ajusticiarlos" por parte de algunas organizaciones políticomilitares de izquierda. Estas últimas también realizaron acciones armadas contra sindicalistas que respondían a la dirección "normalizada" del SMATA, como fue el caso de la muerte de Osvaldo Sánchez, un trabajador de Renault militante de la Alianza Libertadora Nacionalista. Estas operaciones abonaban ese discurso que apuntaba contra "el terrorismo de la guerrilla internacional” y que enarbolaba el lema peronista "para los amigos todo, para los

27. Ídem, 23/09/1975, p. 4; Estrella Roja, Buenos Aires, No 61, 29/09/1975, pp. 17-18; Roberto Nágera, delegado de Transax, miembro de la Comisión Directiva y delegado paritario, integrante del Movimiento de Recuperación Sindical - Lista Marrón del SMATA, militante de Vanguardia Comunista, entrevista realizada en Córdoba el 16/07/2010 por Laura Ortiz.

28. Córdoba, Córdoba, 23/10/1975, p. 4; ídem, 08/10/1975, p. 7; ídem, 10/10/1975, p. 5; Estrella Roja, Buenos Aires, No 61, 29/09/1975, pp. 17-18. 
enemigos ni justicia”. ${ }^{29}$ Por ello, los Cuerpos de Delegados y Comisiones Internas se amparaban bajo la bandera de la autonomía respecto de nucleamientos sindicales y partidos políticos, asegurando que sus decisiones provenían de asambleas de trabajadores y que no estaban "manejados" desde afuera. Probablemente su repudio a los "atentados" hayan tenido que ver más con una táctica pergeñada para evitar ser víctimas del mismo tipo de represión sufrida por el "extremismo"; 30 antes que una verdadera diferencia moral o ideológica con las acciones armadas revolucionarias.

Lo cierto es que hasta junio de 1975, la movilización de las bases mecánicas seguía activa, a juzgar por los pedidos de la Comisión Normalizadora del SMATA que llamaba a sus afiliados a canalizar sus inquietudes por los cuerpos orgánicos del sindicato. ${ }^{31}$ Esto pone en evidencia la separación entre los cuerpos orgánicos y la dirección sindical, que modificó el funcionamiento de todo el sindicato. Si durante el período anterior unos y otros

29. Las declaraciones corresponden a una solicitada de la Comisión Normalizadora del SMATA, Córdoba, Córdoba, 06/10/1975, pp. 4, 7. En Estrella Roja, Buenos Aires, 03/11/1975, No 63, p. 17 se hace referencia al hecho como un ajusticiamiento de un burócrata del SMATA. Por la misma época se efectuó un atentado con explosivos plásticos que dañó el local de la CGT local. Córdoba, Córdoba, 01/10/1975, p. 4.

30. Ídem, 04/10/1975, p. 4. Un año antes, el jefe de policía García Rey había anunciado que "Las personas que no estén en la subversión o en la guerrilla no tienen por qué temer", de manera que ser identificado como guerrillero o subversivo implicaba que se tenía vía libre para recibir los peores tratos de las "fuerzas de seguridad”. Ídem, 08/11/1974, p. 4. Por ello, muchos activistas fabriles que tenían un doble encuadramiento con organizaciones políticas o político-militares, no declaraban públicamente su afiliación, sobre todo cuando eran detenidos por la policía.

31. Ídem, 12/06/1975, pp. 1, 5; ídem, 14/06/1975, p. 7. respondían a las decisiones de las mayorías reunidas en asambleas, en este momento esa dinámica de funcionamiento solo quedó en el nivel de Cuerpos de Delegados y Comisiones Internas. Debido a esto era común escuchar que la dirección "normalizada" del gremio mecánico tomaba decisiones "a espaldas de los trabajadores". ${ }^{32}$ No obstante, paulatinamente, la intervención de esas direcciones sindicales fue frenando la movilización de las bases, aunque no era la única razón por la que las peticiones de los núcleos obreros tendieron a concentrarse en cuestiones más defensivas que ofensivas, tanto en lo económico como en lo político. Este cambio estaba relacionado con modificaciones en la estructura de dominación política, y la acentuación de la represión. Las reivindicaciones económicas de las bases se focalizaron en la oposición a la suspensión, por parte del gobierno nacional, de las cláusulas de reajuste salarial en todos los convenios. Por ello se organizó un abandono de tareas en las principales fábricas en octubre de 1975. En relación a lo político, resultaban enormemente preocupantes las desapariciones de activistas, que se iban multiplicando.

Estos datos invitan a pensar que poco más de un año de intervención del sindicato mecánico no alcanzó para controlar a sus bases. En noviembre de ese año, la masa obrera reunida en asamblea resolvió formar una Comisión Interfabril que asumiese la conducción de la seccional hasta una nueva convocatoria a elecciones. ${ }^{33}$ Aunque ese órgano no llegó a ser aceptado por el SMATA nacional, significó

32. Así lo denunciaron los cuerpos orgánicos de la planta GMD, que convocaron a una asamblea y allí se decidió rechazar el descuento de un día de jornal que había ordenado la comisión normalizadora del SMATA. Ídem, 27/09/1975, p. 7.

33. Ídem, 01/11/1975, p. 3. 
una demostración de la existencia de variadas formas de resistencia obrera por fuera de la institucionalidad "normalizada". Asimismo, la comisión normalizadora del SMATA estaba ausente en las asambleas autoconvocadas por los cuerpos orgánicos de cada una de las fábricas. ${ }^{34}$ En ese contexto, las solidaridades horizontales debieron coordinarse desde otros espacios, menos institucionales, menos orgánicos.

\section{La necesidad de coordinar la resistencia desde otros espacios: la Mesa de Gremios en Lucha}

Desde mediados de 1974, debido a la profundización de la represión y la vigencia de pedidos de captura para las primeras filas de dirigentes sindicales clasistas y combativos que habían sostenido el MSC, se decidió formar un nuevo espacio: la Mesa Coordinadora de Gremios en Lucha. Si bien la Mesa de Gremios no hizo pública una definición por esa opción sindical, los testimonios recogidos indican que entre sus filas se aglutinó al activismo clasista que continuaba en actividad. ${ }^{35}$ Más que una mesa de gremios, se trataba de la confluencia de activistas de distintas agrupaciones sindicales, ya que la mayoría de los sindicatos que habían adherido a una tendencia clasista

34. Ídem, 02/03/1976, p. 2; ídem, 11/03/1976, p. 5; CARRASCO, Daniel, delegado de Renault, miembro de la Mesa de Gremios en Lucha, militante del Peronismo de Base y luego, Espartaco Mayoría, entrevista realizada en Córdoba el 20/09/2011 por Laura Ortiz; Ana María Rodríguez y Rosario Elena, “Onel”, delegadas de ILASA e integrantes del MRS - Lista Marrón del SMATA, entrevista realizada en Córdoba el 30/09/2010 por Laura Ortiz.

35. CARRASCO, Daniel, entrevista citada; VILLA, Juan, entrevista citada. o se habían pronunciado por "la liberación social" en los años previos, en esta etapa estaban intervenidos, disueltos, o nunca habían logrado un reconocimiento legal. Es decir que la Mesa de Gremios venía a apuntalar las redes horizontales que durante los años previos había construido el sindicalismo clasista aunque, ciertamente, el contexto político dificultaría la tarea. La mayoría de sus declaraciones ponían de manifiesto que los reclamos obreros tenían un carácter defensivo. Criticaban la "política antiobrera" del gobierno nacional, la represión empresaria y también el posicionamiento de la CGT regional. En este sentido, se opusieron a la Ley de Asociaciones Profesionales que atacaba la democracia sindical, se quejaron por la dilación de las paritarias y el establecimiento de topes para la discusión, al tiempo que reclamaron el cese de la intervención de algunos sindicatos. También reclamaban la vuelta a la legalidad democrática en Córdoba, $\mathrm{y}$ denunciaron los hechos represivos que tenían al activismo obrero como blanco. Incluso llamaron a desconocer y a repudiar la intervención federal, exigiendo la destitución del interventor Lacabanne y de Choux, su jefe de policía. Los pedidos de aumento salarial buscaban mantener el poder adquisitivo frente al incremento de los precios. ${ }^{36} \mathrm{Al}$ igual que antes el MSC, la Mesa de Gremios estableció alianzas con sectores de izquierda, el Peronismo Auténtico, el MSB y otros. ${ }^{37}$

Por haber podido mantener la estructura institucional, el Sindicato de la fábrica Perkins

36. Córdoba, Córdoba, 18/06/1975, p. 5; ídem, 15/08/1975, p. 4; ídem, 15/09/1975, p. 5; ídem, 28/08/1975, p. 4; ídem, 16/09/1975, p. 5; ídem, $17 / 12 / 1975$, p. 7.

37. Ídem, 02/07/1975, p. 4; ídem, 08/08/1975, p. 4; ídem, 15/08/1975, p. 4; ídem, 15/09/1975, p. 5; ídem, 17/12/1975, p. 7; VILLA, Juan, entrevista citada. 
fue uno de los bastiones fuertes de la Mesa de Gremios. En el resto de los gremios donde las cúpulas sindicales habían sido recuperadas por la "ortodoxia" peronista, durante casi todo este período, continuaron activos los núcleos de resistencia clasista aunque debieron sortear cada vez más dificultades. Por ejemplo, en FIAT Materfer, a pesar de haber pasado varios años de la disolución del SiTraM; los nuevos dirigentes de la UOM no habían podido disciplinar a las bases obreras. Tanto el Cuerpo de Delegados como la CIR de Materfer respondían a la Mesa Reorganizadora Metalúrgica Peronista "Lista Blanca" de la UOM seccional Córdoba. Estaban encabezados por Carlos Disandro, uno de los principales referentes de las 62 Organizaciones que se había alineado con el gobierno de Isabel Martínez de Perón. ${ }^{38}$ Durante su mandato, las condiciones salariales de los trabajadores empeoraron, e incluso hubo suspensiones masivas, anticipos de vacaciones y cierre de la planta por varios días entre septiembre y octubre de $1975 .{ }^{39}$ Sin embargo, los trabajadores y activistas de base que habían formado sus propios Cuerpos de Delegados y comisiones provisorias, aunque no contaban con reconocimiento legal, continuaron en pie de lucha incluso unos días antes del golpe de Estado de 1976, declarando paros, quites de colaboración y "trabajo a tristeza". ${ }^{40}$

Esasituación dedualidadtambién eravivenciada en el sector del caucho, donde las cúpulas

38. Isabel Martínez de Perón había sido elegida como Vicepresidente en 1973, pero asumió la máxima magistratura del Poder Ejecutivo ante la acefalía producida por la muerte del Gral. Juan Domingo Perón, el $1^{\circ}$ de julio de 1974.

39. Córdoba, Córdoba, 19/07/1974, p. 5.

40. Ídem, 18/11/1975, p. 5; ídem, 19/11/1975, p. 5; ídem, 25/11/1975, p. 5; ídem, 19/12/1975, p. 5; ídem, 02/03/1976, p. 2; ídem, 22/03/1976, p. 3.

72 sindicales buscaban frenar la movilización de las bases y las acusaban de ser "subversivas". Durante los años previos, el activismo clasista había intentado formar un sindicato paralelo pero en este contexto debió abortar todos los intentos por institucionalizarlo. El Ministerio de Trabajo había establecido que la única entidad que representaba a los trabajadores de este ramo era el Sindicato de Obreros del Caucho, Anexos y Afines (SOCAYA). Pero esto no implicó que la dirigencia se comprometiera con los problemas laborales del sector ya que ante el cierre de la planta Goma Cord el sindicato se llamó al silencio. Fueron el Movimiento de Recuperación del Caucho y el Sindicato de Perkins los que salieron a repudiar públicamente la actitud empresaria que dejaba sin trabajo a 40 obreros que venían luchando desde hacía 20 días por reclamos salariales y laborales. Luego, el Ministerio de Trabajo dispuso la conciliación obligatoria en el conflicto. El Sindicato del Caucho agradeció al ministro Simó por la gestión y aplaudió la reapertura de la planta, pero el Movimiento de Recuperación del Caucho denunció que la patronal de Goma Cord no reincorporaba a todos los despedidos, aludiendo a la tradicional práctica empresaria de despidos/reincorporaciones selectivas. La ofensiva contra el activismo del Movimiento de Recuperación del Caucho continuó: en marzo de 1976 fue allanado el local del Sindicato de Trabajadores del Caucho, Anexo y Afines (SITRACAF) y fue detenido Rafael Flores Montenegro, su Secretario Adjunto, quien luego de pasar por el Penal de Sierra Chica en Buenos Aires, decidió exiliarse. ${ }^{41}$

41. Ídem, 20/12/1974, p. 4; ídem, 20/02/1976, p. 4; ídem, 21/02/1976, p. 5; ídem, 24/02/1976, p. 3; ídem, 25/02/1976, p. 4; ídem, 10/03/1976, p. 2; FLORES MONTENEGRO, Rafael, Pasión y caída. Memoria de la Mesa de Gremios en Lucha. Argentina, 1973-1976, Ed. 
También en el sector del Calzado la situación era semejante aunque allí el sindicato había sido intervenido por la Central para evitar que la seccional Córdoba fuese ganada por una agrupación clasista. Durante este período, los interventores habían impuesto la verticalidad ortodoxa y una "actitud pro-patronal" que, según denunciaba la Agrupación de Trabajadores del Calzado, frenaba las denuncias colectivas y la movilización de los trabajadores de base, permitiendo que continuaran los despidos y las suspensiones. Según los argumentos patronales, la crisis que afectaba al sector obligaba a cesantear un $80 \%$ de los trabajadores, a los que además, se pretendía indemnizar con zapatos en vez de dinero. ${ }^{42}$ Sin embargo, los trabajadores continuaron luchando por sus derechos e incluso llegaron a ocupar seis fábricas en reclamo de mejoras laborales y salariales. ${ }^{43}$ En este caso, al igual que en otros sindicatos intervenidos, los cuerpos orgánicos y la movilización de las bases comenzaron a funcionar de manera autónoma respecto de la estructura sindical. En cambio, la institucionalidad sindical se mantuvo alineada a la verticalidad "ortodoxa" del peronismo que, desde 1974, había vuelto a hegemonizar el campo político.

Entre los trabajadores lecheros se presentaba una situación similar, sobre todo en el establecimiento La Lácteo SA, donde hubo acciones de trabajo a reglamento y quite de colaboración. Los trabajadores, apoyados por el

Abrazos, Unquillo, 2008.

42. Memorando Policía Federal, Córdoba, 02/09/1975, DGI.cd No 128 "R”; ídem, 06/09/1975, DGI.cd No 133 "R".

43. Ídem, 06/09/1975, DGI.cd No 133 “R”; Córdoba, Córdoba, 16/05/1975, p. 5; ídem, 02/08/1975, p. 4; ídem, 02/08/1975, p. 4; ídem, 07/08/1975, p. 5.
Cuerpo de Delegados de ATILRA (Asociación de Trabajadores de la Industria Lechera de la República Argentina), reclamaban el pago de horas extras y también pedían que se traslade a un supervisor y un empleado que los hostilizaban. Los empresarios denegaron los pedidos de traslados y responsabilizaban al "trabajo a desgano" del desabastecimiento de leche, ya que había disminuido la producción en un 70\%. También en este sector, la activación obrera se relacionaba con las organizaciones político-militares. Por ejemplo, en septiembre de 1974 un "grupo extremista" ocupó la fábrica SanCor para arengar al personal. Casi un año más tarde, la unidad Decididos de Córdoba del Ejército Revolucionario del Pueblo (ERP), colocó una carga explosiva contra un ejecutivo de SanCor. Los mismos declararon que lo hicieron en respuesta a una ocupación de la fábrica por parte de un comando de la JSP que había amedrentado a sus trabajadores. ${ }^{44}$

Todos estos datos dan cuenta de que, a partir del "Navarrazo", la renovada hegemonía de los sectores del peronismo "ortodoxo" en las cúpulas sindicales desprendió la coordinación institucional de los sindicatos con la movilización de las bases en aquellos sectores que habían tenido una identificación con el clasismo. Si bien las redes horizontales que habían sostenido la acción clasista durante los años previos se apuntalaron desde la Mesa Coordinadora de Gremios en Lucha, el nuevo contexto político limitaba las posibilidades de acción a reclamos defensivos. Además, el Estado terrorista profundizaba la sangría de activistas, lo que dificultaba la resistencia.

Una de las principales denuncias que encaró

44. Ídem, 06/09/1974, p. 4; ídem, 19/06/1975, p. 3; ídem, 12/07/1975, p. 4; Estrella Roja, Buenos Aires, No 61, 29/09/1975, p. 17. 
la Mesa de Gremios fueron las que apuntaban a evidenciar la "avalancha represiva" desatada contra los trabajadores y los sectores populares. Según ellos, esta ofensiva antiobrera había comenzado con la destitución del gobierno de Obregón Cano y López, y aseguraban que, en paralelo a la escalada represiva, había descendido el poder adquisitivo de los salarios y aumentado la desocupación. Con esto subrayaban el carácter clasista de esta violencia, al tiempo que incitaban a continuar la lucha para frenar los rastrillajes, allanamientos, detenciones y asesinatos. ${ }^{45}$

Entre 1969 y el 24 de marzo de 1976 esa "avalancha represiva" implicó 31 casos de ejecuciones sumarias y/o desaparición de obreros y sindicalistas cordobeses. Ciertamente, su cantidad aumentó desde fines de $1975 \mathrm{y}$, aunque no tiene parangón con las cifras de muertos y desaparecidos luego del golpe de Estado de 1976; son casos que ponen en evidencia la ejecución de un plan represivo estatal. ${ }^{46}$ En ese plan terrorista del Estado,según el informe de la CONADEP para el período 1976-1983, el 30,2\% de los desaparecidos fueron obreros y, en Córdoba, esa cifra ascendía a $41.90 \% .{ }^{47}$ Aunque muchos de los detenidos-

45. Córdoba, Córdoba, 17/12/1975, p. 7; ídem,14/01/1976, p. 3.

46. Según los registros publicados, en Córdoba hubo 1.010 desaparecidos y/o ejecutados sumariamente como resultado de la política represiva del Estado, entre 1969 y 1983. Cfr. ROMANO, Silvia et al., Vidas y ausencias. Destinatarios de la represión. Córdoba 1969-1983, Universidad Nacional de Córdoba, Córdoba, 2010. De todos ellos, 173 eran obreros, delegados o desarrollaban alguna actividad sindical.

47. Nunca Más, Informe Comisión Nacional sobre la Desaparición de Personas (CONADEP), Eudeba, Buenos Aires, 1984, p. 375; Informe Comisión Nacional sobre la Desaparición de Personas (CONADEP) delegación Córdoba, Córdoba, 1984, p. 109. desaparecidos habían elaborado su identidad política a partir de sus vinculaciones con el sindicalismo clasista y combativo, en varios casos, al momento de su detención y posterior ejecución y/o desaparición hacía tiempo que ya no tenían anclaje directo en el mundo fabril, debido a la profundización de la represión a partir del "Navarrazo".

Quienes eran detenidos podían quedar a disposición de la Justicia o del Poder Ejecutivo Nacional (PEN), y no siempre por una causa judicial. Hay evidencia que demuestra que esas detenciones arbitrarias eran ejecutadas por grupos formados por miembros de comandos peronistas que adscribían a la policía, al ministerio de Bienestar Social, o a algún sindicato ortodoxo. ${ }^{48}$ Algunos historiadores, especialistas sobre estos temas, aseguran que esta represión hizo blanco fácil en los militantes sindicales de base, ya que no contaban con una estructura partidaria que los contuviera para entrar en la clandestinidad. ${ }^{49}$ No obstante, muchos activistas identificados con el sindicalismo clasista y combativo en Córdoba debieron dejar las fábricas a partir de 1974,ya que sabían que eran perseguidos. Entre 1974 y 1976 cada vez fue mayor la cantidad

48. Actuaciones labradas con motivo de la privación ilegitima de la libertad donde resultara damnificado Hugo Stanislao Ochoa. Tribunal Instrucción $2^{\circ}$ Nominación, Letra "A", $\mathrm{N}^{\circ}$ 210, iniciado 21/11/75, Caja 1, serie Judicialización y Política, Archivo Histórico del Poder Judicial de Córdoba.

49. JAMES, Daniel, Resistencia e integración. El peronismo y la clase trabajadora argentina, 1946-1976, Siglo XXI Editores, Buenos Aires, 2005, p. 325. Cfr. BASUALDO, Victoria y LORENZ, Federico, "Los trabajadores industriales argentinos en la primera mitad de la década del '70: propuestas para una agenda de investigación a partir de análisis comparativos de casos", en Páginas, Rosario, 2012, Año 4, № 6, pp. 135-136. Disponible en: $<$ http://revistapaginas.unr.edu.ar/index.php/RevPaginas/ article/view/97/97> 
de activistas que tuvieron que "esconderse", debilitando aún más las redes de organización obrera. Si bien las resistencias obreras continuaron, el renovado contexto represivo hizo que las modalidades de movilización clasista y combativa se transformasen. Ante la fragmentación de las redes de militancia, la Mesa de Gremios en Lucha, comenzó a practicar una especie de socialización de su base social, donde cada dirigente no solo lo era de su gremio o de su fábrica, sino de todos los que se referenciaban con la Mesa de Gremios.

El dirigente sindical, por más combativo que sea, siempre construye y se erige en una especie de custodio de su base social. Un representante de esa base social que, no está dispuesto a compartirla con nadie... La Mesa de Gremios en Lucha, tenía movilidad en sus representantes, trasladaba sus dirigentes de un lado a otro. En el sentido de que yo como dirigente de la Mesa de Gremios en Lucha iba a las asambleas de la Alimentación, de los compañeros de Luz y Fuerza o de cualquier otro gremio afín a la mesa. Y más allá de que estuviese o no su referente sindical, yo hablaba con los compañeros, los compañeros me reconocían y los compañeros tomaban las decisiones de la misma manera que con sus propios dirigentes... y eso pienso que fue un paso más en la construcción de una forma de lucha que nos garantizaba a pesar de que fuésemos secuestrados o desaparecidos, que la gente con algún compañero iba a seguir funcionando. ${ }^{50}$

Pero, además, estas nuevas formas de activismo dan cuenta de la cotidiana amenaza del secuestro y desaparición por razones políticas y también de una reducción de las posibilidades para una acción sindical ofensiva. Estas nuevas modalidades defensivas continuaron durante

50. Daniel Carrasco, entrevista citada. el período posterior al golpe de Estado de 1976 y constituyeron formas de expresión de la oposición obrera a la Dictadura. ${ }^{51}$

\section{Conclusiones}

Durante la intervención federal que siguió al "Navarrazo" en Córdoba, la coordinación de la represión estatal y paraestatal fue conformando un Estado terrorista. Esta situación afectó a los trabajadores clasistas ya que su activismo comenzó a ser represaliado, al tiempo que, se intervenían los sindicatos identificados con esa tendencia. En el caso del SMATA, varios frentes de conflicto -contra la patronal, el Estado y las cúpulas nacionales del SMATA y la CGT central y regional- dificultaron las posibilidades de enfrentar la intervención.

Desde mediados de 1974 el activismo cordobés clasista y combativo de los distintos sectores productivos, que estaba quedando sin estructura sindical que lo contuviera, se aglutinó primero en el MSC y luego en la Mesa Coordinadora de Gremios en Lucha. La mayor parte de sus integrantes conformaban las bases obreras que continuaban activadas a pesar de que sus dirigencias habían sido cooptadas por sectores alineados al peronismo "ortodoxo", tal el caso del SMATA, las plantas de FIAT, del caucho, de calzado y los lecheros. Dentro de estos sindicatos se vivía una situación de dualidad donde el activismo clasista continuó en actividad, aunque de manera autónoma, respecto de su comisión directiva.

Hacia 1975, el empeoramiento de la

51. Cfr. POZZI, Pablo, La oposición obrera a la dictadura (1976-1982), Editorial Imago Mundi, Buenos Aires, 2008 [1988]. 
situación económica estructural y el cierre de las discusiones paritarias que dificultaron posibles aumentos salariales fueron un freno a la movilización clasista. En este clima de repliegue y para evitar la caída de jornales por huelgas, los paros y movilizaciones fueron mucho más escasos que la táctica del trabajo a reglamento y quite de colaboración. A esta modalidad de protesta los empresarios solían llamarla "trabajo a desgano", para generar una asociación de sentidos con la holgazanería antes que con un reclamo de derechos. En los primeros meses de 1976, previo al Golpe, los trabajadores habían comenzado a llamarlo "trabajo a tristeza", probablemente en vistas a la irreversibilidad de la situación estructural que afectaba a toda la Argentina.

Las direcciones sindicales "ortodoxas" y los cambios en la estructura de dominación política habían cortado los canales de expresión pública y masiva de los descontentos obreros. Esas condiciones políticas y sindicales hicieron que el activismo en la Mesa de Gremios en Lucha implementase nuevas formas de organización como fue la "socialización de las bases obreras" entre distintos gremios. Su función fue, principalmente, apuntalar las redes horizontales que durante los años previos había construido el sindicalismo clasista aunque, ciertamente, el contexto político dificultaría la tarea. La organización de la represión contra los activistas y dirigentes clasistas se constituyó desde esferas institucionales (el ministerio de Trabajo, la Justicia, la policía y el Ejército) y extrainstitucionales, en particular, desde la JSP y los comandos peronistas. La evidencia indica la responsabilidad de estas instituciones y grupos parapoliciales, como también la de los empresarios, en la persecución violenta del activismo clasista, que hoy deberían juzgarse como delitos de lesa humanidad. 


\section{Bibliografía}

ALTAMIRANO, Carlos, Peronismo y cultura de izquierda, Siglo XXI Editores, Buenos Aires, 2011.

ARICÓ, José M., La cola del diablo. Itinerario de Gramsci en América Latina, Siglo XXI, Buenos Aires, 2014 [2005].

BASUALDO, Victoria y LORENZ, Federico, "Los trabajadores industriales argentinos en la primera mitad de la década del '70: propuestas para una agenda de investigación a partir de análisis comparativos de casos”, en Páginas, Rosario, 2012, No 6, pp. 123-157. Disponible en: <http://revistapaginas.unr.edu. ar/index.php/RevPaginas/article/view/97/97>

BRENNAN, James, "El clasismo y los obreros. El contexto fabril del 'sindicalismo de liberación' en la industria automotriz cordobesa, 1970-75”, en Desarrollo Económico, Buenos Aires, 1992, V.XXXII, No 125 , pp. 3-22.

BRENNAN, James y GORDILLO, Mónica, Córdoba rebelde. El Cordobazo, el clasismo y la movilización social, De la Campana, Buenos Aires, 2008.

DA SILVA CATELA, Ludmila y JELIN, Elizabeth (compiladoras) Los archivos de la represión: documentos, memoria y verdad, Siglo XXI, Madrid, 2002.

FLORES MONTENEGRO, Rafael, Pasión y caída. Memoria de la Mesa de Gremios en Lucha. Argentina, 1973-1976, Editorial Abrazos, Unquillo, 2008.

FRASER, Ronald, Recuérdalo tú y recuérdalo a otros. Historia oral de la guerra civil española, Crítica, Barcelona, V.I, 1979.

JAMES, Daniel, Resistencia e integración. El peronismo y la clase trabajadora argentina, 1946-1976, Siglo XXI Editores, Buenos Aires, 2005.

LARA MEZA, Ada Marina, MACÍAS GLORIA, Felipe y CAMARENA OCAMPO, Mario (coordinadores) Los oficios del historiador: taller y prácticas de la historia oral, Universidad de Guanajuato, México, 2010.

LAVERDI, Robson, "Raymond Williams y la historia oral: relaciones sociales constitutivas", en Palabras y silencios, México, 2010, V. V, N², pp. 21-32;

LÖBBE, Héctor, La guerrilla fabril: clase obrera e izquierda en la Coordinadora de Zona Norte del Gran Buenos Aires: 1975-1976, Ediciones RyR, Buenos Aires, 2009.

LORENZ, Federico, Algo parecido a la felicidad. Una bistoria de la lucha de la clase trabajadora durante la década del setenta (1973-1979), Edhasa, Buenos Aires, 2013.

OLLIER, María Matilde, El fenómeno insurreccional y la cultura politica (1969-1973), CEAL, Buenos Aires, 1986. 
ORTIZ,María Laura, “Córdoba y sus vaivenes. Transformaciones coyunturales y continuidades estructurales en la relación entre Estado, empresarios y mundo obrero (1969-1976)”, en Estudios, Córdoba, juliodiciembre 2014, No 32, pp. 149-167. Disponible en: <https://revistas.unc.edu.ar/index.php/restudios/ article/view/11588/12003>

POZZI, Pablo y SCHNEIDER, Alejandro, Los “setentistas”. Izquierda y clase obrera (1969-1976), EUDEBA, Buenos Aires, 2000.

POZZI, Pablo, La oposición obrera a la dictadura (1976-1982), Editorial Imago Mundi, Buenos Aires, 2008[1988].

ROMANO, Silvia et. al., Vidas y ausencias. Destinatarios de la represión. Córdoba 1969-1983, Universidad Nacional de Córdoba, Córdoba, 2010.

SANTELLA, Agustín y ANDÚJAR, Andrea, El Perón de la fábrica éramos nosotros. Las luchas metalúrgicas de Villa Constitución, 1970-1976, Desde el Subte, Buenos Aires, 2007.

SCHWARZSTEIN, Dora (organizadora), La historia oral, CEAL, Buenos Aires, 1991.

SERVETTO, Alicia, “Córdoba en los prolegómenos de la dictadura. La política del miedo en el gobierno de Lacabanne”, en Estudios, Córdoba, otoño 2004, No 15, pp.143-156. Disponible en: < https://revistas. unc.edu.ar/index.php/restudios/article/view/13542/13710>

WERNER, Ruth y AGUIRRE, Facundo, Insurgencia obrera en la Argentina 1969-1976. Clasismo, coordinadoras interfabriles y estrategias de la izquierda, Ediciones IPS, Buenos Aires, 2009. 